\title{
Article \\ Quantifying the Training and Match-Play External and Internal Load of Elite Gaelic Football Players
}

\author{
Shane Malone ${ }^{1,2, *}$, Kieran Collins ${ }^{1,2}$, Allistair McRobert ${ }^{1}(\mathbb{D})$ and Dominic Doran ${ }^{1}$ \\ 1 The Tom Reilly Building, Research Institute for Sport and Exercise Sciences, Liverpool John Moores \\ University, Henry Cotton Campus, 15-21 Webster Street, Liverpool L3 2ET, UK; \\ kieran.collins@tudublin.ie (K.C.); a.p.mcrobert@ljmu.ac.uk (A.M.); D.A.Doran@ljmu.ac.uk (D.D.) \\ 2 Gaelic Sports Research Centre, Department of Science, Technological University Dublin, Tallaght, \\ 24 Dublin, Ireland \\ * Correspondence: shane.malone@mymail.ittdublin.ie
}

Citation: Malone, S.; Collins, K.; McRobert, A.; Doran, D. Quantifying the Training and Match-Play External and Internal Load of Elite Gaelic Football Players. Appl. Sci. 2021, 11, 1756. https://doi.org/10.3390/ app11041756

Academic Editor: Mark King Received: 16 December 2020 Accepted: 11 February 2021 Published: 16 February 2021

Publisher's Note: MDPI stays neutral with regard to jurisdictional claims in published maps and institutional affiliations.

Copyright: (c) 2021 by the authors Licensee MDPI, Basel, Switzerland. This article is an open access article distributed under the terms and conditions of the Creative Commons Attribution (CC BY) license (https:// creativecommons.org/licenses/by/ $4.0 /)$

\begin{abstract}
The current investigation quantified the training and match-play load of elite Gaelic football players across a two-season period using global positioning system technology (GPS), rating of perceived exertion (RPE) and sessional rating of perceived exertion (sRPE). Total weekly workload variables were collected across GPS, RPE, and sRPE across thirty-six elite Gaelic footballers (mean \pm SD, age: $26 \pm 5$ years; height: $177 \pm 8 \mathrm{~cm}$; mass: $81 \pm 7 \mathrm{~kg}$ ) from one elite squad during a two-season observational period. External training load variables included: Total distance (m), High speed running $\left(\mathrm{m} ; \geq 17.1 \mathrm{~km} \cdot \mathrm{h}^{-1}\right)$, Sprint distance $\left(\mathrm{m} ; 22 \mathrm{~km} \cdot \mathrm{h}^{-1}\right)$, Accelerations $(\mathrm{n})$, Average metabolic power $\left(\mathrm{W} \cdot \mathrm{kg}^{-1}\right)$, High-power distance $\left(\mathrm{m} ; \geq 25 \mathrm{~W} \cdot \mathrm{kg}^{-1}\right)$. Internal load variables included: sRPE and RPE. Repeated measures ANOVA were used to understand the differences in loading patterns across phases, position, and week types when significant main effects were observed a Tukey's post hoc test was applied and standardized effect sizes were calculated to understand the practical meaning of these differences. When total weekly loading across phases was considered total load was significantly greater in club 1 and provincial 1 with these phases showing the highest loading for players when compared to all other phases ( $p \leq 0.001$; ES: 2.95-7.22; very large). Furthermore, in-season 1 was greater for total loading when compared to in-season 2 and both championship phases ( $p \leq 0.05$; ES: 0.47-0.54; small). Total distance in training was greater during preseason 1 when compared to all other phases of the season ( $p \leq 0.001$; ES: 2.95-7.22; very large). During the in-season period, training based total distance was higher during provincial 1 when compared to other phases with similar trends across all measures $(p \leq 0.005)$. Finally, a positional profile for load measures was observed, with weekly context (match or non-match) having an impact on the internal and external loading players experienced across phases. The current data provide useful information for practitioners on the training periodization currently present within the elite Gaelic football training process. Specifically, the data provide positional profiles of loading across weekly and segmented phased of an elite Gaelic football season. These data can increase understanding as to the periods of increased and decreased loading across different phases of an elite Gaelic football season, while providing a framework for future analysis concerning Gaelic football periodization.
\end{abstract}

Keywords: positional profile; periodization; load monitoring; team sports; GPS

\section{Introduction}

The evolving nature of elite Gaelic football has resulted in a requirement for increased scientific knowledge regarding the optimization of training planning and structure. Indeed, Gaelic football competition is multicyclical in nature with the typical seasonal calendar including preseason games, national league games, provincial games, and All-Ireland games across a yearly calendar [1,2]. For example, during a typical national league game week, these amateur athletes may go through a weekly round of competition, recovery, training, and a subsequent round of competition. The above training and competition 
calendar results in an increased requirement of backroom staff to appreciate the typical training loads completed by elite Gaelic football players on a weekly and segmental basis across a seasonal period. These analyses allow staff prepare players to maximize performance across the seasonal period, but also for players and teams to peak at the appropriate time of the season namely the All-Ireland series which is deemed the most important competition across the Gaelic football calendar [2]. In line with this demand, there has been a proliferation of quantitative athlete monitoring approaches and strategies within elite Gaelic football teams, that are executed on daily basis [2].

The recruitment of sports science and strength and conditioning staff to the backroom teams of elite Gaelic football teams has resulted in the emergence of training load monitoring practices within these teams, with this exponentially growing across the last number of years owing to the need to monitor individual responses to training practices. Initially, practitioners were limited to the use of subjective scales to monitor players training load across weekly and seasonal periods (e.g., pre-season, in-season, club, provincial and championship phases). However, in recent times advancements in technology have resulted in the utilization of global positioning systems (GPS) and accelerometers within Gaelic football teams [3-7]. These two training load constructs of internal (RPE, sRPE) and external (GPS) load represent the two main monitoring mechanisms utilized by coaching staff to understand players loading across daily, and weekly phases during the season [8,9], with a combination of these two training factors typically manipulated for training planning, volume, and intensity [10,11].

The ability of conditioning staff within Gaelic football to understand internal and external training load allows for more effective training prescription, for example, GPS technology can provide important objective information pertaining to training drills, internal training games, specific conditioning interventions, global training sessions and global match-play. These systems allow for in-depth analysis on the running profiles of athletes with measures such as total distance travelled, total high-speed running completed, average metabolic power and mechanical loading through acceleration and deceleration analysis typically reported [12-14]. Furthermore, the utilization of the rating of perceived effort methodology across sessions (s-RPE), provides practitioners with actionable and useful information in determining the internal load of athletes; such that the physiological stress to the external load, can effectively be captured $[1,2,15,16]$. These data allow coaches and conditioning staff to manipulate athletes through periods of high and low training volume and intensity to ensure these athletes are optimally balanced within the fitness-fatigue paradigm to provide increased readiness for maximal performance levels during competition. This approach has now been adopted by several teams as part of their training monitoring systems across elite Gaelic football teams [1,2,17].

Periodization plans require careful manipulation of training volume and intensity to increase performance levels $[8,18,19]$. The appropriate application of periodization strategies allows for a more effective prescription of training that respects the natural peaks and troughs of players physical status across a training phase [20]. Accordingly, a balance between training stress, life stressors, match-play, and recovery are significant to improve performance levels and reduce subsequent injury risk $[1,8]$. Due to the lack of current data available in elite Gaelic football players, the periodization practices of elite teams are currently unknown. Anecdotally, teams will often employ a coach's training philosophy based on years of coaching experience. However, it is unknown whether the periodization practices adopted demonstrate the necessary variation in training load that is typically associated with existing periodization practices [20]. Additionally, it is unknown if differences exist in loading strategies between playing positions, with positional-difference information limited to match-play data [3-7].

Finally, the context within which training load data is gathered is of importance as it will allow coaches to better plan and prescribe training at both a team and individual player level. As such, the application of player monitoring across both external load and internal load during training sessions is required. Moreover, within Gaelic football, it is 
unknown, how training load is manipulated across specific competition phases currently. Given the above, the purpose of this study was to quantify the training load employed by an elite Gaelic football team across a two-season period including positional, match and non-match week and specific seasonal phase analysis using current applied monitoring methods.

\section{Materials and Methods}

\subsection{Approach to Problem}

External and internal training load data were collected across a two-season observational period within an elite Gaelic football team. External training load was quantified through the utilization of global positioning system technology (GPS; 4-Hz, VX Sport, Lower Hutt, New Zealand), with internal training load quantified through the application of the session rating of perceived exertion (Borg Scale: 1-10) methodology. All data were prospectively recorded over a two-season period in elite Gaelic football players (National League Division 1 and All Ireland Championship). Data were collected across the competitive season and was divided by (1) position, (2) match and non-match weeks and (3) distinct phases for descriptive purposes. These phases were Pre-season (DecemberJanuary), In-season 1 (Feb-March: National League Game 1-National League Game 3), In-Season 2 (March-April: National League Game 3-National League Game 6), Club 1 (April: Club Month), Provincial 1 (May-June: Provincial championship), Championship 1 (July-August: All Ireland Knockout Phase 1), Championship 2 (August-September: AllIreland Semi-Final and All Ireland Final). The data recorded included all training and match-play external and internal load data resulting in 22,896 individual observations across the duration of the analysis. The external and internal training load analysis presented in each block represents the average weekly total within the given season block to account for differences in the number of weeks within blocks. To analyze the distribution of training load by mode, a similar approach was taken to that of Ritchie et al. [8] where training was categorized into "training" (team training, field-based conditioning, sports specific training), "gym" (upper-body weights, lower-body weights, plyometrics, olympic lifts), "match-play" (Competitive games), "individual skills" (Gaelic football-specific skills training completed with the coach or by the player alone), and "other" (boxing, cycling, swimming, altitude training, heat training, and cross-training). Finally, match and nonmatch weeks with a similar schedule were analyzed against one another to standardize this comparative analysis.

\subsection{Participants}

The current investigation was a prospective cohort study of elite Gaelic football players competing at the highest level of competition in Gaelic football (National League Division 1 and All-Ireland). Data were collected across thirty-six $(n=36)$ players (Mean $\pm \mathrm{SD}$, age: $26 \pm 5$ years; height: $177 \pm 8 \mathrm{~cm}$; mass: $81 \pm 7 \mathrm{~kg}$ ) over a two-season period. Players competed in matches within the national football league, provincial championships, and the All-Ireland series during both seasons. The senior level playing experience of the current squad was $8 \pm 6$ years. Playing experience within a Gaelic football context refers to the time a player is registered to the senior elite playing squad. Currently in Gaelic football, players can be released from elite squads to return to sub-elite competition where management see appropriate. The study was approved by the local institute's research ethics committee and written informed consent was obtained from each participant.

\subsection{Training Load Analysis}

Internal training load data were obtained through subjective means via the RPE-based method [21]. Data was collected 10-30 min following every field-based, indoor, and gamebased session, as well as all strength training and cross-training conditioning sessions in the gym. To obtain a training impulse or total load value, the RPE was multiplied by session duration, providing a session RPE (sRPE) value for all training and game 
events [10]. Players RPE was individually collected through the utilization of a customdesigned application on a portable tablet (iPad, Apple Inc, Cupertino, California, USA). Each player selected his RPE rating by touching the respective score on the tablet, which was then automatically saved under the player's profile. This method helped minimize factors that may influence a player's RPE rating, such as peer pressure and replicating other players' ratings [9]. During the observational period, all players wore the same GPS unit $(4 \mathrm{~Hz}, \mathrm{VX}$ Sport, Lower Hutt, New Zealand) for each training and match sessions to minimize interunit error [3-7]. The device was activated, and the satellite lock established for a minimum of $15 \mathrm{~min}$ before the commencement of each match [22]. GPS technology is a valid and reliable way of measuring distance and movement speeds in a range of high-speed, intermittent, contact, and noncontact sports [12]. The number of satellites for GPS was satisfactory during all competitive match-play events: range: 10-15 with an average of $12.3 \pm 3$ satellites per training and match-play activity, respectively. The horizontal dilution of position (HDOP) which reflects the geometrical arrangement of the satellites and is related to both the accuracy and quality of the signal was not collected, which is a limitation of the current study. Specific external training load parameters obtained from GPS include total distance $(\mathrm{m})$; relative total distance $\left(\mathrm{m} \cdot \mathrm{min}^{-1}\right)$; highspeed running $\left(\mathrm{m} ; \geq 17.1 \mathrm{~km} \cdot \mathrm{h}^{-1}\right)$ (HSR); very high-speed running $\left(\mathrm{m} ; \geq 19.8 \mathrm{~km} \cdot \mathrm{h}^{-1}\right)$ (VHSR); sprint distance $\left(\mathrm{m} ; \geq 22 \mathrm{~km} \cdot \mathrm{h}^{-1}\right)$; accelerations $\left(\mathrm{n} ; \geq 3 \mathrm{~m} \cdot \mathrm{s}^{-2}\right)$; high-power meters $\left(\mathrm{m} ; \geq 25 \mathrm{~W} \cdot \mathrm{kg}^{-1}\right)$; average metabolic power $\left(\mathrm{W} \cdot \mathrm{kg}^{-1}\right)$ [2-7]. Each player wore the device inside a custom-made vest supplied by the manufacturer across the upper back between the left and right scapulae.

\subsection{Statistical Analysis}

Prior to analysis all data were log transformed. All data were analyzed within SPSS Version 22, (IBM, UNICOM, Mission Hills, CA, USA) and are reported as mean \pm SD unless stated. Prior to analysis all data were analyzed for normality through a Shapiro-Wilks assessment with a Levene's test utilized to understand the homogeneity of variances within the data set. Any data that failed to meet these assessments were removed from further analysis with statistical significance set at an accepted level of $p<0.05$. In the present study, time-period (mesocycles, microcycles and training days) and player's position (FB, $\mathrm{HB}, \mathrm{MF}$, $\mathrm{HF}$, and $\mathrm{FF}$ ) were treated as independent variables, with all internal and external loading variables (sRPE and GPS variables) treated as dependent variables within the data set. Across the data set a series of repeated measure ANOVAs were completed to understand the variation across internal and external training loads across specific seasonal phases, position, and match week context (match or non-match). When significant main effects were observed a Tukey's post hoc test was applied. Standardized effect sizes (ES) were calculated with $<0.2,0.21-0.6,0.61-1.20,1.21-2.00$, and 2.01-4.0 representing trivial, small, moderate, large, and very large differences, respectively [23].

\section{Results}

\subsection{Analysis of Internal Load by Phase}

The average internal load across the seasonal phases was $2163 \pm 954$ AU. Analysis of variance revealed significant main effects for weekly loading across phases ( $\mathrm{F}=111.8$, $p<0.05)$. When total weekly loading across phases was considered total load was significantly greater in club 1 ( $p \leq 0.05$; ES: 0.33-0.97; small-moderate) and provincial 1 ( $p \leq 0.05$; ES: 0.36-1.03; small-moderate) when compared to all other phases. Furthermore, in-season 1 was greater for total loading when compared to in-season 2 ( $p=0.045 ;$ ES: $0.44 ;$ small) and both championship ( $p \leq 0.05$; ES: 0.47-0.54; small) phases. Match-play loading was greater during championship 2 ( $p \leq 0.001$; ES: 0.30-1.35; small-large) and in-season $2(p \leq 0.001$; ES: 0.06-1.01; trivial-moderate) when compared to other phases of the season. Club 1 was significantly lower for match-play load when compared to other phases $(p \leq 0.001$; ES: 0.91-1.35; moderate-large). Training based load was greater in pre-season versus all other phases of the season ( $p \leq 0.001$ : ES: 0.86-2.63; moderate-very large), with in-season 1 ( $p<0.05$; 
ES: 0.66-1.41; moderate-large) and provincial 1 ( $p<0.05$; ES: 0.67-1.51; moderate-large) showing higher loading when compared to other phases. Championship 2 showed the lowest training-based load when compared to other phases of the year $(p<0.05$; ES: 0.79-2.63; moderate-very large). Gym session loading was consistent across the season, lower gym loading was reported in the final two phases of the season when compared to other phases $(p<0.001$; ES: 0.65-1.51; moderate-large). Finally, individual skill loading was significantly higher during club 1 ( $p<0.05$; ES: 0.72-2.81; moderate-very large) when compared to other phases of the season (Table 1, Figure 1).

Table 1. Analysis of weekly session RPE (sRPE) across specific phases of an elite Gaelic football season. Data presented as mean $\pm \mathrm{SD}$.

\begin{tabular}{ccccccc}
\hline Phase & Total Load & Match-Play & Training & Individual Skills & Gym Sessions & Other \\
\hline Pre-season & $2180 \pm 850^{\mathrm{b}}$ & - & $1080 \pm 321^{\mathrm{a}}$ & $240 \pm 244$ & $520 \pm 123$ & $340 \pm 176^{\mathrm{b}}$ \\
In-Season 1 & $2280 \pm 1150^{\mathrm{b}}$ & $610 \pm 230$ & $790 \pm 350^{\mathrm{b}}$ & $220 \pm 130$ & $410 \pm 230$ & $250 \pm 210^{\mathrm{b}}$ \\
In-Season 2 & $1840 \pm 800^{\mathrm{a}}$ & $710 \pm 370^{\mathrm{a}}$ & $520 \pm 130$ & $120 \pm 90$ & $400 \pm 100$ & $90 \pm 110$ \\
Club 1 & $2680 \pm 1140^{\mathrm{a}}$ & $390 \pm 250$ & $560 \pm 340$ & $600 \pm 230^{\mathrm{a}}$ & $570 \pm 200$ & $560 \pm 120^{\mathrm{a}}$ \\
Provincial 1 & $2650 \pm 870^{\mathrm{a}}$ & $560 \pm 130$ & $780 \pm 310^{\mathrm{b}}$ & $450 \pm 180^{\mathrm{b}}$ & $530 \pm 120$ & $330 \pm 130^{\mathrm{b}}$ \\
Championship 1 & $1810 \pm 920$ & $690 \pm 270^{\mathrm{a}}$ & $530 \pm 290$ & $170 \pm 110$ & $320 \pm 140^{\mathrm{a}}$ & $100 \pm 110$ \\
Championship 2 & $1705 \pm 950$ & $780 \pm 320^{\mathrm{a}}$ & $395 \pm 180$ & $115 \pm 80$ & $325 \pm 240^{\mathrm{a}}$ & $90 \pm 130$ \\
\hline
\end{tabular}

Total load: (a) Significant increase in total load between club 1, provincial 1 and all other phases $(p \leq 0.05)$. (b) Significant increase in total load during the preseason and in-season 1 when compared to in-season 2, championship 1 and championship 2 ( $p \leq 0.05)$. Match-play: (a) Increase in match load versus all other phases $(p \leq 0.001)$, Training: Increase in load versus all other phases $(p \leq 0.05)$. (b) Significant increase in load between in-season 1 and provincial 1 when compared to other phases $(p \leq 0.05)$. Individual skills: (a) Significant increase in loading during club 1 versus all other phases $(p \leq 0.05)$. (b) Increase in load versus other phases $(p \leq 0.05)$. Gym Sessions: (a) Significant decrease in load versus all other phases $(p \leq 0.001)$. Other: (a): Significant increase in load versus other phases $(p \leq 0.05)$. (b) Increase in load versus other phases $(p \leq 0.05)$.

\subsection{Analysis of External Load by Phase}

The external load of elite Gaelic footballers across specific variables is presented within Table 2. Analysis of variance revealed significant main effects for weekly distance covered across phases $(\mathrm{F}=389.3, p<0.05)$. Total distance in training was significantly greater during pre-season 1 when compared to all other phases of the season $(p \leq 0.001$; ES: 2.95-7.22; very large). Within the in-season period training based total distance was higher during provincial 1 when compared to other phases ( $p \leq 0.05$; ES: 0.16-2.32; trivial-large). When match-play total distance was considered championship 2 had the highest total distance ( $p \leq 0.05$; ES: 0.10-0.67; trivial-moderate) when compared to other phases followed by championship 1 and in-season 2 periods. Similar trends were observed for high-speed running and very high-speed running. When sprint distance was considered the pre-season 1 phase ( $p \leq 0.05$; ES: 0.33-1.69; small-large) showed the highest sprint distance completed with this significantly reduced across phases for the duration of the season (Table 2). The distribution of high-power meters $\left(\mathrm{m} ; \geq 25 \mathrm{~W} \cdot \mathrm{Kg}^{-1}\right)$ and average metabolic power $\left(\mathrm{P}_{\text {met }}\right.$; $\mathrm{W} \cdot \mathrm{Kg}^{-1}$ ) across seasonal phases is shown in Figure 2. Increases in loading were seen between pre-season and in-season 1 ( $p=0.038$; ES: 0.32; small). Additionally, increases in loading were noted between club 1 and provincial 1 ( $p=0.021$; ES: 0.98; moderate) and pre-season 1, in-season 1 ( $p=0.021$; ES: 0.89; moderate) and in-season 2 ( $p=0.004$; ES: 1.45; large). When average metabolic power was considered this variable was seen to increase from preseason phase to in-season 1 ( $p=0.045$; ES: 0.78; moderate) with further increases noted during the provincial 1 phase ( $p \leq 0.05$; ES: 0.58-1.44; moderate-large) when compared to the rest of the seasonal phases.

\subsection{Positional Analysis of External Load by Phase}

Analysis across specific seasonal phases and position for specific external load measures are shown in Figure 3. Analysis of variance revealed significant main effects for position on the external loading patterns across phases $(\mathrm{F}=987.3, p<0.05)$. Irrespective of the phase of the season position specific profile was observed for external load. Across all seasonal phases, half back ( $p \leq 0.05$; ES: $0.33-0.58$; moderate), midfield ( $p \leq 0.05$; ES: 
1.16-2.32; large), half forward ( $p \leq 0.05$; ES: 0.45-0.66; moderate) players covered significantly greater volumes of total distance when compared to full back and full forward players. Similar trends were observed for high-speed running across the phases of the season. When metabolic power indices were considered midfield players ( $p \leq 0.05$; ES: 0.26-0.59; smallmoderate) showed significant increases in high power meters and average metabolic power across all phases when compared to the half back and half forward lines, with additional significant increases observed for half back ( $p \leq 0.05$; ES: 0.26-0.92; small-moderate) and half forward ( $p \leq 0.05$; ES: $0.22-0.98$; small-moderate) lines when compared to full back and full forward lines across similar measures.

\subsection{Match and Non-Match Weeks across Position and External Load}

The effect of weekly match context on specific external load measures are presented in Figure 4. During non-match weeks players were shown to have significant $(p=0.045$; ES: 0.31-0.89; small-moderate) increases in total distance when compared to match weeks. Similar trends were observed for high-speed running across match and non-match weeks. Increases in high power meters ( $p=0.035$; ES: 0.31 ; small $)$ and average metabolic power ( $p=0.035$; ES: 0.35 ; small $)$ were also observed across non-match weeks when compared to match weeks. 


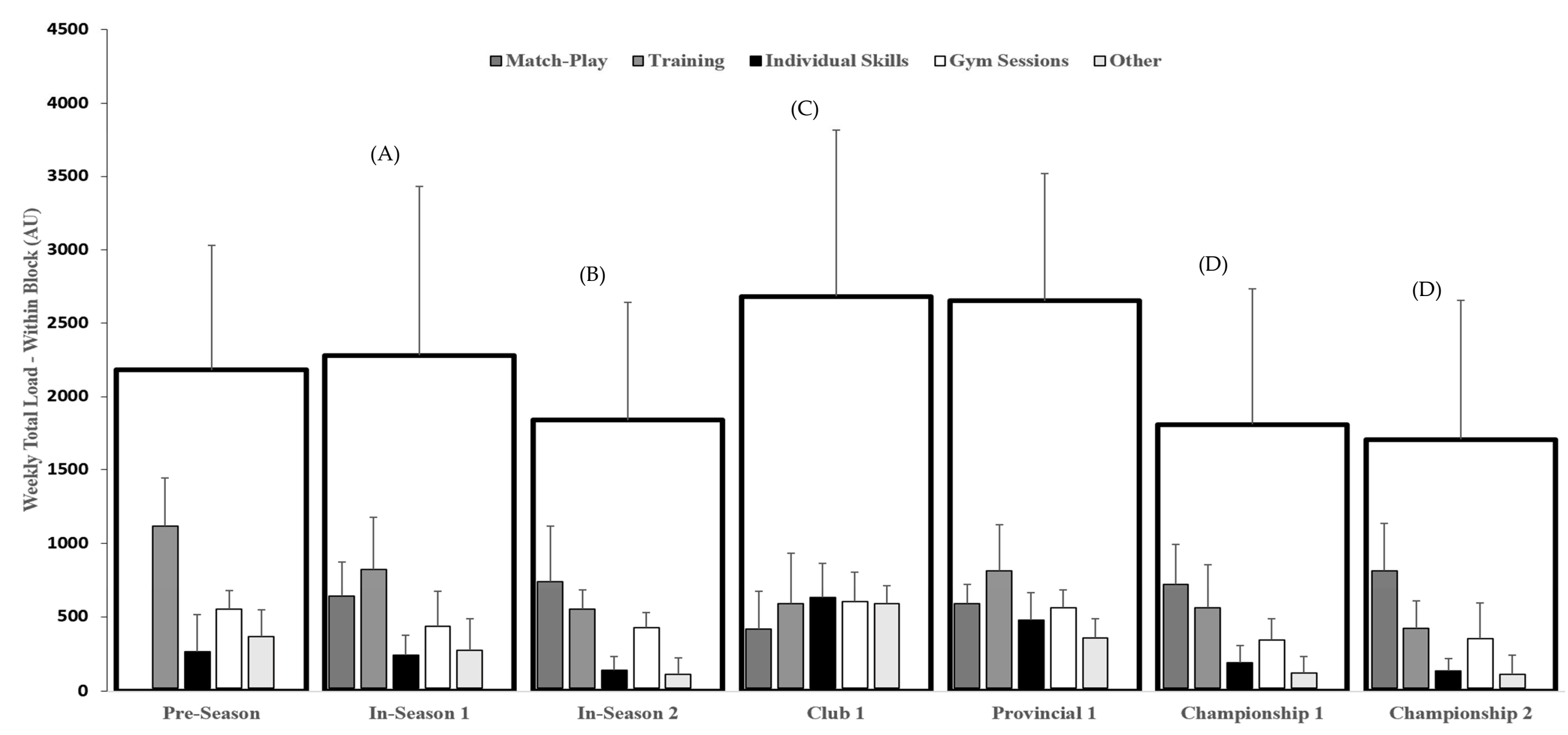

Figure 1. The session RPE (sRPE) training load distribution across phases (large bar) and all modes (small bars) mean \pm SD. Abbreviations: AU, arbitrary units. (A) Significant increase in loading between pre-season and in-season 1 ( $p \leq 0.05)$. (B) Significant decrease in loading between pre-season, in-season 1 and in-season 2 ( $p \leq 0.05)$. (C) Significant increase in load between club 1 and provincial 1 and pre-season, in-season 1 and in-season 2 ( $p \leq 0.05)$. (D) Significant decrease in load between in-season 1 , club 1 , provincial 1 , and championship 1 and championship $2(p \leq 0.05)$. 
Table 2. Analysis of external training load variables across phases for specific volume and mechanical metrics. Data presented as mean \pm SD.

\begin{tabular}{|c|c|c|c|c|c|c|c|c|c|c|c|c|}
\hline \multirow{2}{*}{ Phase } & \multicolumn{2}{|c|}{ Duration (min) } & \multicolumn{2}{|c|}{ Total Distance (m) } & \multicolumn{2}{|c|}{ High Speed Distance (m) } & \multicolumn{2}{|c|}{ Very High-Speed Distance (m) } & \multicolumn{2}{|c|}{ Sprint Distance (m) } & \multicolumn{2}{|c|}{ Accelerations (n) } \\
\hline & Training & $\begin{array}{l}\text { Match- } \\
\text { Play }\end{array}$ & Training & Match-Play & Training & Match-Play & Training & Match-Play & Training & $\begin{array}{l}\text { Match- } \\
\text { Play }\end{array}$ & Training & Match-Play \\
\hline Pre-season & $155 \pm 50^{a}$ & - & $22,369 \pm 2300^{a}$ & - & $2813 \pm 890^{a}$ & - & $1812 \pm 876^{a}$ & - & $619 \pm 418^{a}$ & - & $181 \pm 98$ & - \\
\hline In-Season 1 & $120 \pm 35$ & $72 \pm 5$ & $12,546 \pm 3456$ & $8999 \pm 1098$ & $1687 \pm 810$ & $1513 \pm 786$ & $1300 \pm 867$ & $796 \pm 509$ & $489 \pm 355^{b c}$ & $371 \pm 317$ & $191 \pm 77^{\mathrm{a}}$ & $171 \pm 90$ \\
\hline In-Season 2 & $110 \pm 35$ & $72 \pm 5$ & $11,354 \pm 2980$ & $9321 \pm 1287^{b}$ & $1403 \pm 934$ & $1797 \pm 874$ & $1270 \pm 987$ & $834 \pm 528$ & $479 \pm 213^{b c}$ & $401 \pm 365$ & $178 \pm 91$ & $181 \pm 93$ \\
\hline Club 1 & $150 \pm 30^{\mathrm{a}}$ & $65 \pm 3^{a}$ & $13,877 \pm 2877$ & $8679 \pm 1321$ & $1787 \pm 879$ & $1498 \pm 599$ & $1501 \pm 766^{b}$ & $799 \pm 578$ & $410 \pm 341^{c}$ & $290 \pm 189^{c}$ & $166 \pm 87$ & $165 \pm 77^{a}$ \\
\hline Provincial 1 & $150 \pm 35^{\mathrm{a}}$ & $75 \pm 6$ & $14,356 \pm 3076^{b}$ & $9321 \pm 1087$ & $2002 \pm 913^{b}$ & $1698 \pm 531$ & $1400 \pm 789^{b}$ & $845 \pm 678^{b}$ & $345 \pm 244^{c}$ & $421 \pm 231$ & $171 \pm 89$ & $181 \pm 87$ \\
\hline Championship 1 & $95 \pm 40$ & $77 \pm 4$ & $10,356 \pm 3211^{c}$ & $9412 \pm 1098^{b}$ & $1635 \pm 956$ & $1865 \pm 987$ & $1398 \pm 979$ & $978 \pm 567^{a}$ & $123 \pm 101$ & $461 \pm 321$ & $181 \pm 88$ & $185 \pm 88$ \\
\hline Championship 2 & $90 \pm 36$ & $74 \pm 7$ & $8876 \pm 1297^{c}$ & $9541 \pm 1256^{a}$ & $1514 \pm 866$ & $1986 \pm 654^{\mathrm{a}}$ & $1100 \pm 992$ & $986 \pm 766^{a}$ & $108 \pm 99$ & $489 \pm 298^{a}$ & $177 \pm 64$ & $183 \pm 84$ \\
\hline
\end{tabular}

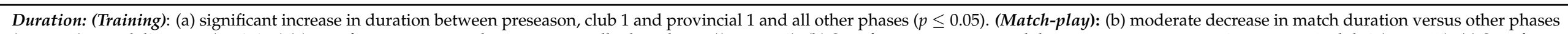

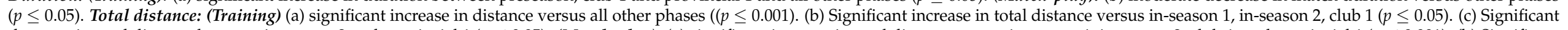

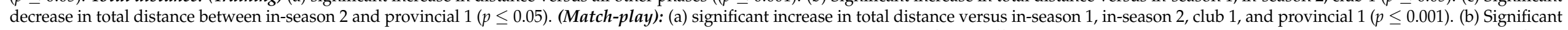

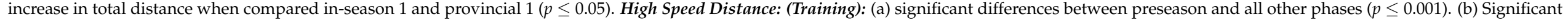

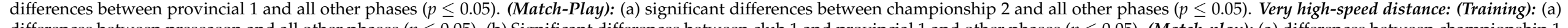

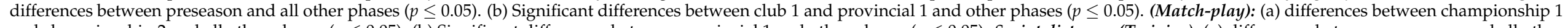

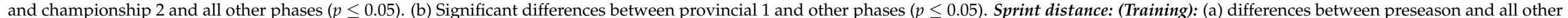

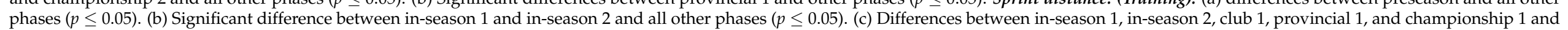
championship 2 ( $p \leq 0.05)$. Accelerations (Training): difference between in-season 1 and other phases $(p \leq 0.05)$. (Match-play): differences between club 1 and other phases $(p \leq 0.05)$. 


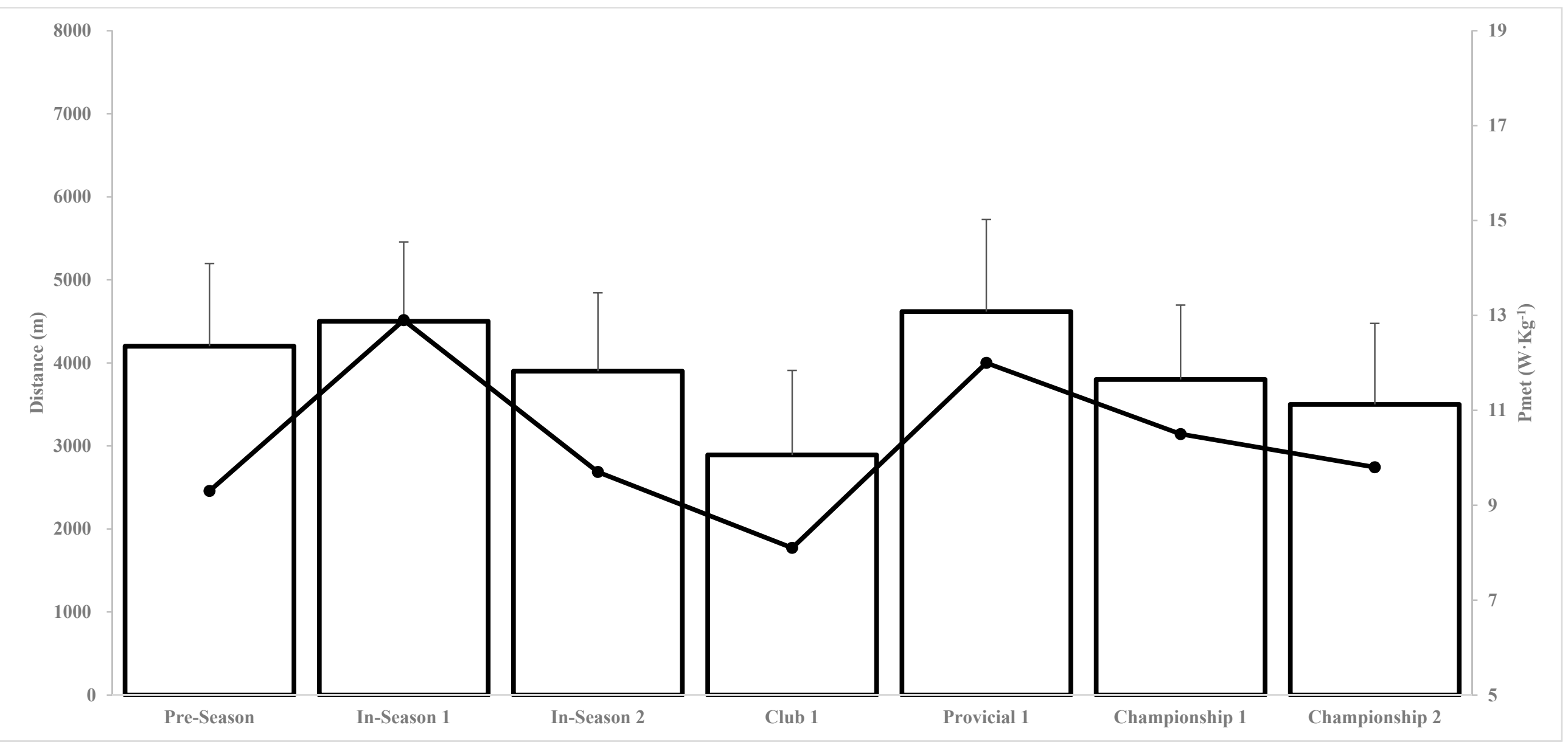

Figure 2. The distribution of high-power meters boxes $\left(\mathrm{m} ; \geq 25 \mathrm{~W} \cdot \mathrm{kg}^{-1}\right)$ and average metabolic power line $\left(\mathrm{P}_{\mathrm{met}} ; \mathrm{W} \cdot \mathrm{kg}^{-1}\right)$ across seasonal phases within an elite Gaelic football team. All data presented as mean \pm SD. 

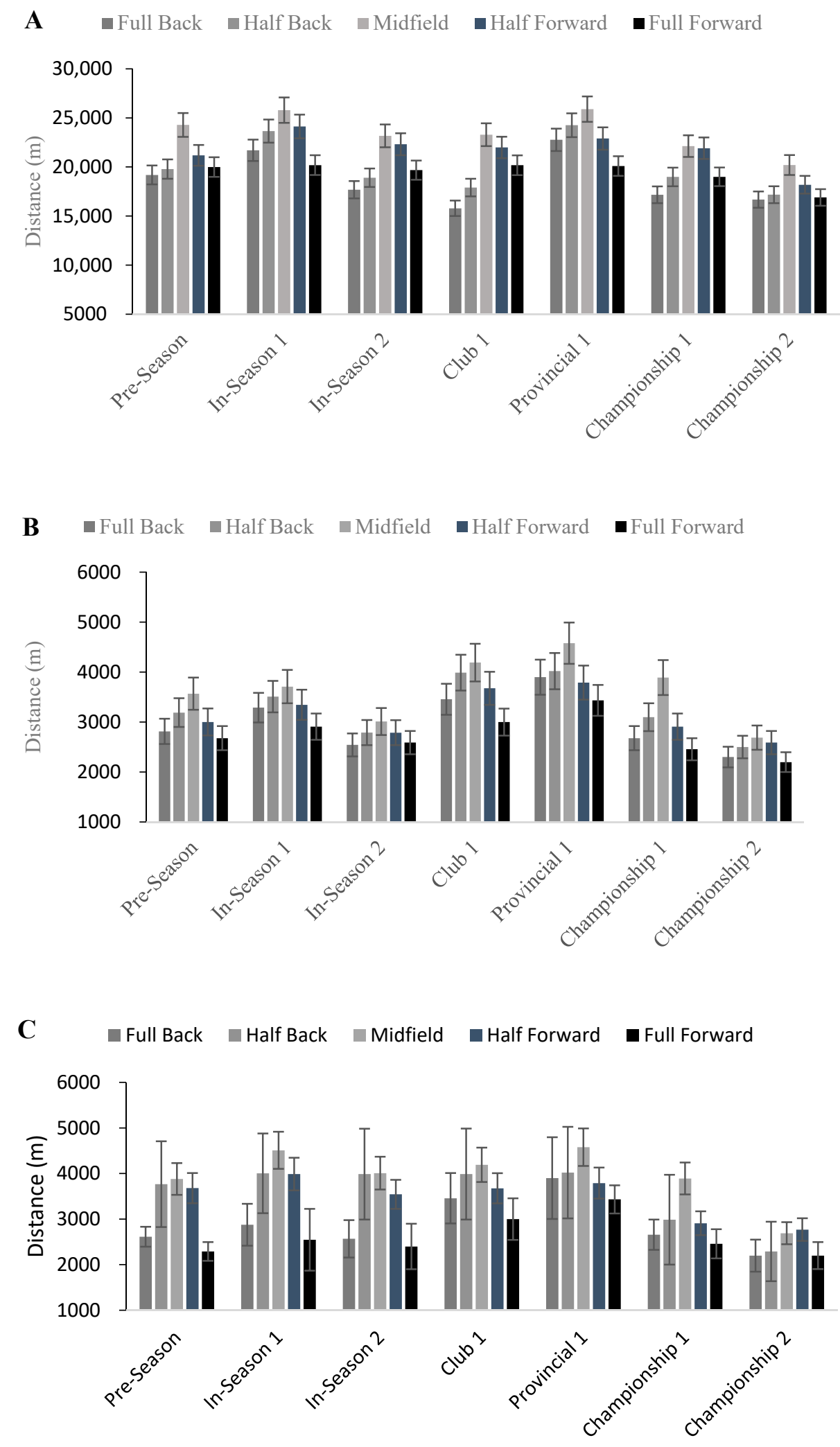

Figure 3. Cont. 
D $\quad$ Full Back $\quad$ Half Back $\quad$ Midfield $\quad$ Half Forward $\square$ Full Forward

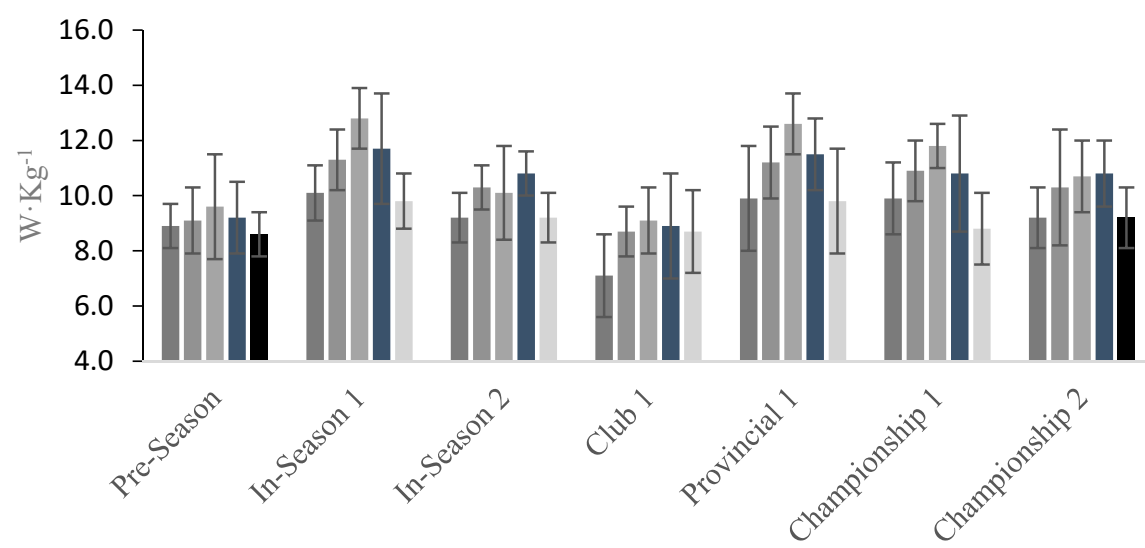

Figure 3. The positional distribution of external load across phases for (A) total distance (m), (B) high speed running $\left(\mathrm{m} ; \geq 17.1 \mathrm{~km} \cdot \mathrm{h}^{-1}\right),(\mathrm{C})$ high-power distance $\left(\mathrm{m} ; \geq 25 \mathrm{~W} \cdot \mathrm{kg}^{-1}\right)$, and (D) average metabolic power $\left(\mathrm{P}_{\text {met }} ; \mathrm{W} \cdot \mathrm{kg}^{-1}\right)$. Data presented as mean $\pm \mathrm{SD}$.
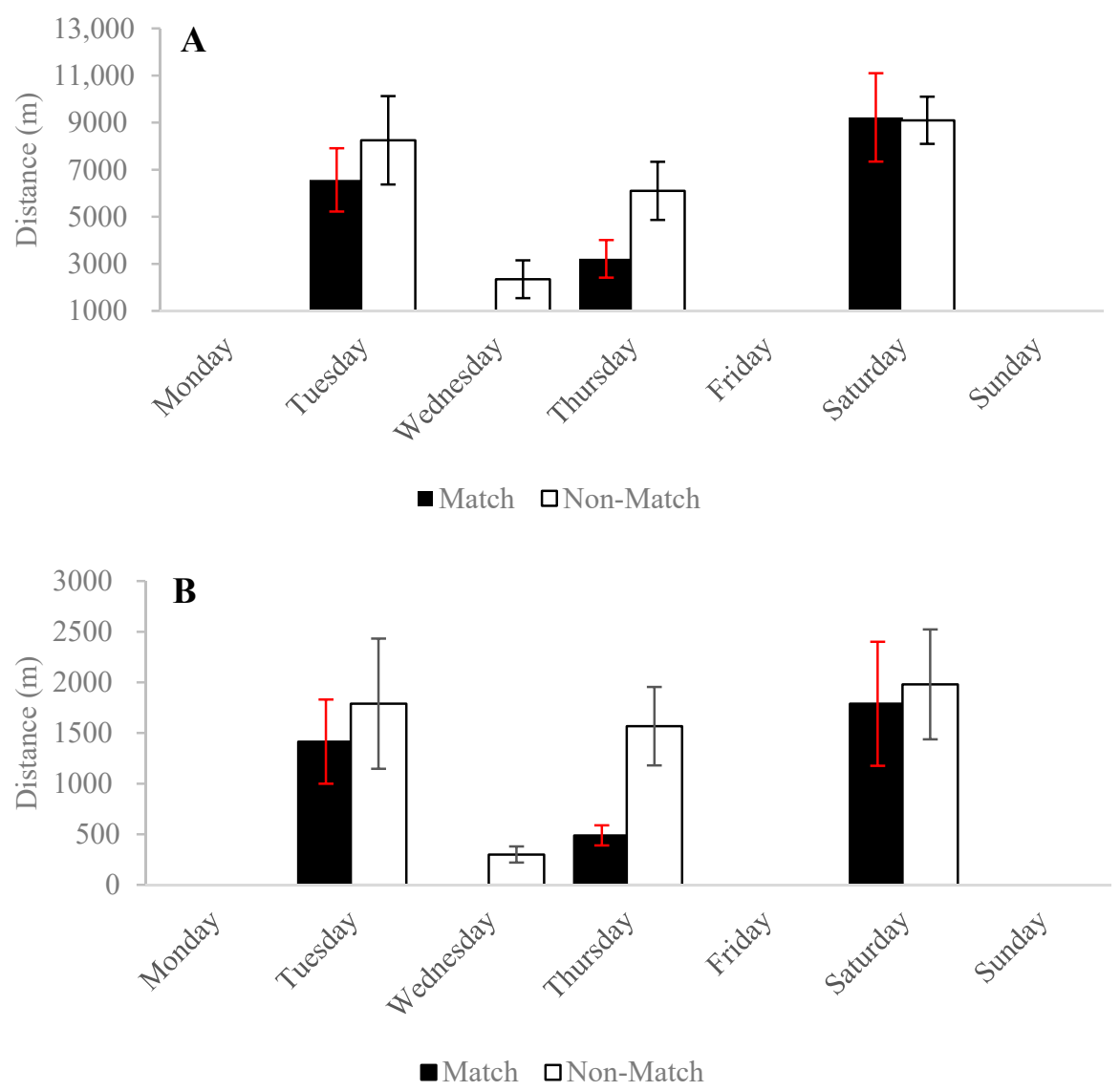

Figure 4. Cont. 

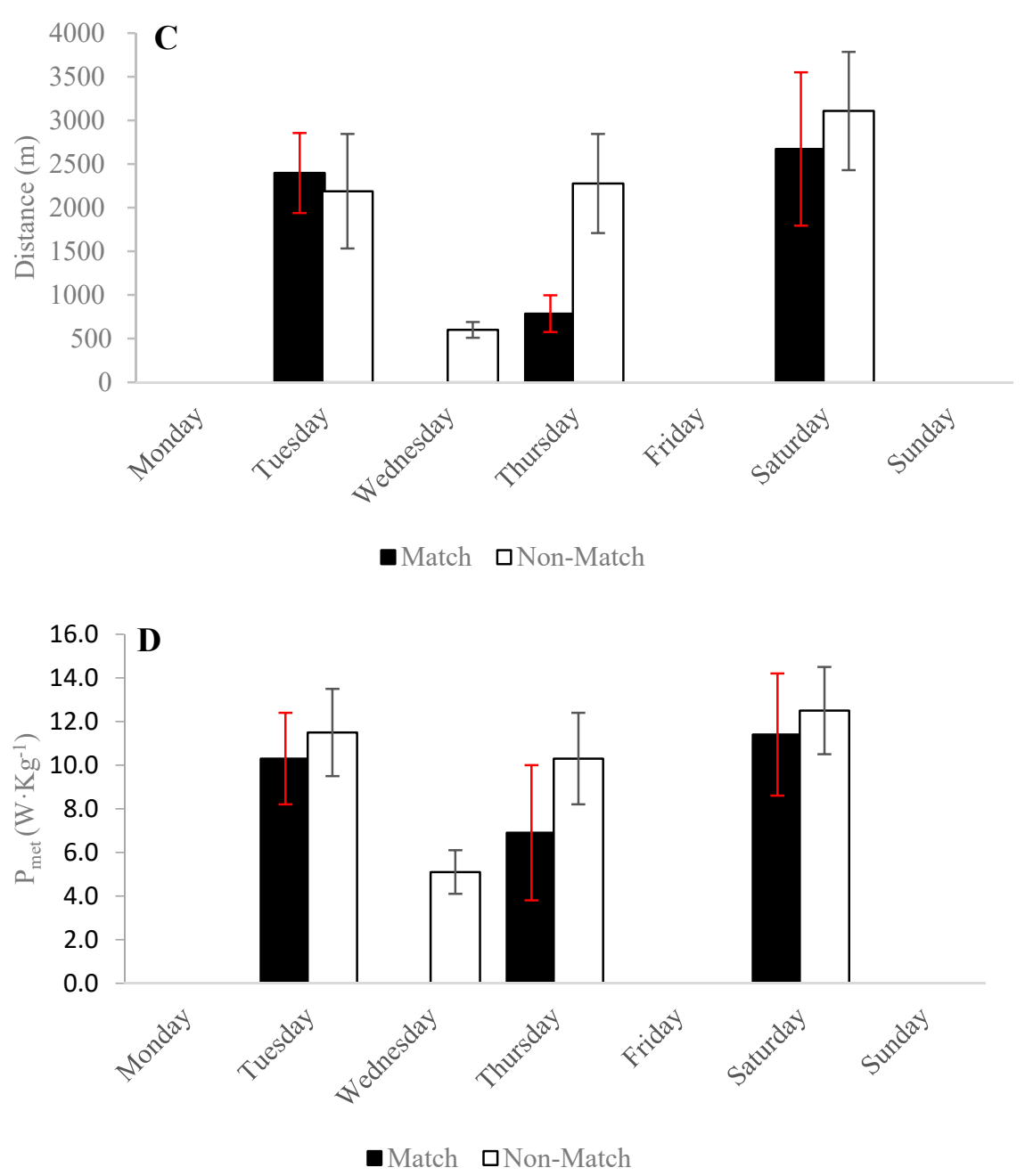

Figure 4. The distribution of external load with respect to match week context (match or non-match weeks) for (A) total distance $(\mathrm{m}),(\mathbf{B})$ high speed running $\left(\mathrm{m} ; \geq 17.1 \mathrm{~km} \cdot \mathrm{h}^{-1}\right),(\mathbf{C})$ high-power distance $\left(\mathrm{m} ; \geq 25 \mathrm{~W} \cdot \mathrm{kg}^{-1}\right)$, and $(\mathbf{D})$ average metabolic power $\left(\mathrm{P}_{\text {met }} ; \mathrm{W} \cdot \mathrm{kg}^{-1}\right)$. Data presented as mean $\pm \mathrm{SD}$.

\section{Discussion}

The current investigation aimed to quantify the internal and external training load experienced by an elite Gaelic football team across a two-season period. The investigation applied a specific analysis across position, match week context, and seasonal phase. The data indicated that total weekly internal load across phases was greater in club 1 and provincial 1 when compared to all other phases. Furthermore, in-season 1 showed greater internal loading when compared to championship phases. The data showed a consistent trend for a positional profile for external training load measures across all seasonal phases with a bell-shaped curve noted across weekly external training load. Furthermore, external loads were highest within pre-season and provincial 1 when compared to other phases of the season. Finally, the investigation reported for the first time within elite Gaelic football a differentiation in loading across match and non-match weeks. Our data showed that non-match weeks were consistently higher for external training load when compared to match weeks.

Present data agrees with existing literature where pre-season training load is greater than in-season training load $[1,8,11,24]$. Within Gaelic football for the first time, we report the internal loading across specific constructs of training load composition such as training, individual skills, gym, and other formats of conditioning. The main findings from the present observational data are that the pre-season period has the highest internal training load when compared to all other phases of the season. The above observation is not 
surprising given that the emphasis during pre-season is to build and rebuild the generic and specific fitness parameters of elite Gaelic football players following the detraining that potentially occurs during the off-season. As such, players will complete maximal testing both within the gym and on-field during this phase with these measures used to prescribe general running based conditioning that accompanies more specific methods of training such as simulated phases of play, small-sided games, and skill-based drills [25]. The increase in loading across training may be also related to reduced fitness capacities impacting players perception of load. Indeed, previous literature has shown that aerobic fitness as measured through a 1-km time trial was associated with increased or decreased perception of loading as measured through session rating of perceived exertion [15,16].

Furthermore, the in-season 1, club 1, and provincial 1 phases were shown to have the greatest accumulation of total loading when compared to other phases of the year, these results appear to flow with the natural layout of the current Gaelic football competition calendar. Indeed, within the in-season 1 period teams are traditionally in competition within the national league while also aiming to concurrently increase the physical capacities of players, as such increased loads within this phase are not surprising as the phase acts a building phase in line with the pre-season phase of the year. The club 1 phase of the season is a dedicated club month where elite players return to their sub-elite club teams for club championship with a cessation in elite intercounty activity during this phase. However, players will typically utilize this phase as an additional building phase as highlighted within the current data by an increase in "individual skills" and "other" internal load across this specific phase. Therefore, it can be speculated that players may engage in additional conditioning sessions to maintain what they perceive to be the required running abilities to compete upon the resumption of elite activity within the provincial 1 phase. Furthermore, within the provincial 1 phase there was an increased loading paradigm employed within the current team, this is not a surprising finding given that this phase typically houses training camp(s) that focuses on technical and conditioning elements. Additionally, coaches will try to increase players specific tactical knowledge and understanding given that this phase represents the start of the All-Ireland competition. When match load was considered, it appears that the importance of the match impacted player perceived loading with an increase in loading across match-play during the in-season 2 and championship 2 phases where the national league and All-Ireland finals would typically take place. Furthermore, match load was seen to represent $38-55 \%$ of the weekly total loading within elite Gaelic football players.

To further understand the training load practices of an elite Gaelic football team the external load of the team was also analyzed across positions and phases of the season. The study found a consistent trend for a distinct positional profile within the external loading of Gaelic football players across the seasonal phases. This may be related to the specific conditioning and training strategy employed within the current observational cohort. Indeed, the philosophy of the coach was towards simulated phases of play or small sided games with a positional condition within them, as such players were consistently exposed to game specific situations resulting in game specific distances being covered across specific phases. When a phase specific analysis of the data was completed the data showed that total distance in training was greater during pre-season 1 and provincial 1 when compared to other phases. Interestingly, we report that match-play total distance increased across the championship 2 and in-season 2 periods suggesting that match-play demands increase as the Gaelic football season progresses. Similar trends were observed for high-speed running and very high-speed running. Coaches may need to consider the observations noted across high-power meters $\left(\mathrm{m} ; \geq 25 \mathrm{~W} \cdot \mathrm{kg}^{-1}\right)$ and average metabolic power $\left(\mathrm{P}_{\mathrm{met}} ; \mathrm{W} \cdot \mathrm{kg}^{-1}\right)$ across seasonal phases within the current investigation. Indeed, given the known association between average metabolic power and aerobic capacity within elite Gaelic football players [13], the data suggests a reduction in aerobic capacity across the elite Gaelic football season as reported by an overall reduction from the highest point in the season (In-Season 1) and the championship 2 phase. These findings have been shown 
across many team sports and may be related to shift in focus from aerobic based nonspecific conditioning towards more specific methods such as simulated game play and small-sided games. While important within team sports these methodologies may reduce players mechanical and metabolic efficiency over time resulting in lower average metabolic power accumulation within training and match-play. Additionally, management and performance staff need to manage the fitness-fatigue paradigm of players during the most important phases of the year to ensure the team taking to field is the strongest from a running and technical perspective $[1,26,27]$.

Not surprising and consistent with the shift in training focus from fitness increases to fatigue management. Coaches within the current study were shown to be able to plan effective in-season training programs that facilitate the preparation for and recovery from competition $[2,18,26,28,29]$. Not surprisingly, Gaelic coaches typically will plan out specific coaching and conditioning goals across phases of the season. Indeed, all these are tailored towards match-weeks, with the aim of all performance and management staff to ensure the maximal performance capabilities within all match-play situations. Performance has previously been defined as fitness minus fatigue [18-20,29]. Given these observations the aim of all performance staff is to ensure maximal freshness within players preceding all match scenarios. Within our current investigation, match weeks showed a consistent trend for lower external training load across both running and metabolic power measures. This may be explained by management planning specifically for the opposition they will face at the weekend, as such conditioning coaches will generally allow coaches have one session where players can accrue elements of fatigue typically on Tuesday of a match week. Post the Tuesday session players and coaches alike are focused on the weekends match-play. Therefore, the Thursday session is typically a skills and specific set play oriented session in a similar fashion to those observed within rugby union. Furthermore, the importance of match-play appears to have influenced the training load across the current investigation with reductions in loading across in-season 2 . This phase is typically when the national league final takes place with a further reduction in loading observed within the championship phases where the All-Ireland competition would take place. The data reported within the current investigation may show that coaches adopted a pre-competition reduction in load to protect against injury, such as that shown in rugby league where reductions in load in the preseason reduce risk of injury and result in greater improvements in physical fitness [26,27]. Collectively, these data suggest that training and game load is periodically managed before competition, possibly to reduce risk of injury and improve potential match performance $[1,8,26]$.

The combination of internal (s-RPE) and external (GPS) load monitoring is important for practitioners in understanding the totality of training load accumulated across specific meso, micro and macrocycles during a Gaelic football season. Indeed, the integration of both internal- and external-load measures may be a viable and feasible monitoring strategy within these amateur athletes given the extensive external stressors these athletes encounter post training within their everyday lives a monitoring system that aims to assess all constructs of load may be even more appropriate within the Gaelic football cohort. Moreover, load distribution is largely affected according to the time of the season, with the pre-season containing the highest amounts of conditioning and skills while the in-season is characterized by a focus on competition and recovery. Despite these novel findings within Gaelic football cohorts, the authors acknowledge that the current investigation is a case study of one team. However, the current team were monitored across a two-season period thus providing an increased data set in comparison to most team sport periodization literature. Whilst it is acknowledged that the current data is specific to the current cohort of players and the specific coaching style and conditioning philosophies employed across the analysis period. Indeed, it must be acknowledged that the performance staff of the current team were well educated on specific loading practices and philosophies to maintain performance and reduce injury risk as such across specific situations players were managed across the season for reduced training loads this may have impacted the typical weekly 
loadings observed within the current investigation. In addition, the training practices presented in the current study are likely to be different at the individual level. Future research should aim to understand the dose-response relationship of the reported internal and external variables analyzed by performance staff within Gaelic football and changes in fitness characteristics of players across a season. Furthermore, given the known practical issues conditioning coaches face across a seasonal period it would be prudent to understand the different loading patterns between starters and nonstarters in Gaelic football. With a greater understanding required across how these specific players are managed from a conditioning and training perspective. Finally, it is important that support staff within elite Gaelic football teams understand the knowledge base of coaches and management with respect to sport science to provide the most effective monitoring system to these key stakeholders, as such an analysis of knowledge and understanding of management is important and is warranted. Future research should aim to understand both coaching and player perception of the fundamental application of sport science and training load monitoring within elite Gaelic football teams. Additionally, there should be a focus on how training load directly relates to changes in physical performance metrics and injury profiles within elite Gaelic football. Finally, data derived from multiple teams and differing competitive levels of the national leagues would also enhance our understanding of training load within the elite Gaelic football setting. Therefore the creation of a centralized database for Gaelic football teams from an internal and external training load perspective may be prudent and provide increased insights into the match and training demands of these players.

\section{Conclusions}

To conclude, the current investigation systematically quantified the training load employed by an elite Gaelic football team across a two-season period using a combination of internal and external training load methodologies. The data from this study revealed that the Gaelic football pre-season contains higher training loads, when compared to the inseason period where there is a shift in load distribution such that $38-55 \%$ of load is obtained via competition. Given the amateur status of Gaelic football athletes, an increase in the understanding of the specific distribution of load across a season may aid practitioners in planning and structuring future seasonal plans. Furthermore, given the increased external stresses placed on these athletes there may be a need to switch practitioner philosophies towards a model of freshness over fitness and conditioning athletes more in a game-style model as opposed to nonspecific conditioning elements. Additionally, there is a need to compare specific periodization strategies within elite Gaelic football to understand if the current investigations data is in-line or an outlier when compared to other elite Gaelic football teams. The current study is a case-study analysis of a single team; the distribution and variation of load across the season may vary between other elite teams and standards of play. Future research incorporating other modes of load monitoring, as well as examining, years of experience, and individual responses to specific training blocks, will help Gaelic football practitioners in understanding the dose-response variation to components of fitness across a season.

Author Contributions: All authors contributed to the manuscript across the following key definitions: Conceptualization, S.M., K.C. and D.D.; Data curation, S.M.; Formal analysis, S.M. and D.D.; Investigation, S.M.; Methodology, S.M., K.C., A.M. and D.D.; Project administration, A.M. and D.D.; Resources, K.C., A.M. and D.D.; Software, K.C. and D.D.; Supervision, K.C., A.M. and D.D.; Visualization, S.M.; Writing - Original draft, S.M. and K.C.; Writing-Review and editing, K.C., A.M. and D.D. All authors have read and agreed to the published version of the manuscript.

Funding: This research received no external funding.

Institutional Review Board Statement: The study was conducted according to the guidelines of the Declaration of Helsinki and approved by the institutional Ethics Committee of Technological University Dublin, Tallaght (REC-PGR5R-201920; Approval Date: 19 July 2019). 
Informed Consent Statement: Informed consent was provided by all subjects who took part in the current investigation.

Acknowledgments: The authors would like to thank the management, backroom team and players of the Gaelic football team investigated within the current manuscript who provided their time and commitment to the current investigation across the observational period.

Conflicts of Interest: The authors declare no conflict of interest.

\section{References}

1. Malone, S.; Roe, M.; Doran, D.A.; Gabbett, T.J.; Collins, K.D. Protection Against Spikes in Workload with Aerobic Fitness and Playing Experience: The Role of the Acute:Chronic Workload Ratio on Injury Risk in Elite Gaelic Football. Int. J. Sports Physiol. Perform. 2017, 12, 393-401. [CrossRef] [PubMed]

2. Cullen, B.D.; McCarren, A.L.; Malone, S. Ecological validity of self-reported wellness measures to assess pre-training and pre-competition preparedness within elite Gaelic football. Sport Sci. Health 2020, 1-10. [CrossRef]

3. Malone, S.; Solan, B.; Hughes, B.; Collins, K. Duration specific Running performance in Elite Gaelic Football. J. Strength Cond. Res. 2017. [CrossRef] [PubMed]

4. Malone, S.; Solan, B.; Collins, K. The Running Performance Profile of Elite Gaelic Football Match-Play. J. Strength Cond. Res. 2017, 31, 30-36. [CrossRef]

5. Malone, S.; Solan, B.; Collins, K.D.; Doran, D.A. Positional Match Running Performance in Elite Gaelic Football. J. Strength Cond. Res. 2016, 30, 2292-2298. [CrossRef]

6. Mangan, S.; Malone, S.; Ryan, M.; McGahan, J.; O’Neill, C.; Burns, C.; Warne, J.; Martin, D.; Collins, K. The influence of match outcome on running performance in elite Gaelic football. Sci. Med. Footb. 2017, 1, 272-279. [CrossRef]

7. Mangan, S.; Malone, S.; Ryan, M.; Mc Gahan, J.; Warne, J.; Martin, D.; O’Neill, C.; Burns, C.; Collins, K. Influence of Team Rating on Running Performance in Elite Gaelic Football. J. Strength Cond. Res. 2018, 32, 2584-2591. [CrossRef]

8. Ritchie, D.; Hopkins, W.G.; Buchheit, M.; Cordy, J.; Bartlett, J.D. Quantification of Training and Competition Load Across a Season in an Elite Australian Football Club. Int. J. Sports Physiol. Perform. 2016, 11, 474-479. [CrossRef]

9. Burgess, D.; Drust, B. Developing a physiology-based sports science support strategy in the professional game. In Science and Soccer: Developing Elite Performers; Williams, M., Ed.; Routledge: Oxon, UK, 2012; pp. 372-389.

10. Impellizzeri, F.M.; Rampinini, E.; Marcora, S.M. Physiological assessment of aerobic training in soccer. J. Sports Sci. 2005, 23, 583-592. [CrossRef]

11. Malone, J.J.; Di Michele, R.; Morgans, R.; Burgess, D.; Morton, J.P.; Drust, B. Seasonal Training-Load Quantification in Elite English Premier League Soccer Players. Int. J. Sports Physiol. Perform. 2015, 10, 489-497. [CrossRef]

12. Buchheit, M.; Allen, A.; Poon, T.K.; Modonutti, M.; Gregson, W.; Di Salvo, V. Integrating different tracking systems in football: Multiple camera semi-automatic system, local position measurement and GPS technologies. J. Sports Sci. 2014, 32, 1844-1857. [CrossRef] [PubMed]

13. Malone, S.; Shovlin, A.; Collins, K.; McRobert, A.; Doran, D. Is the metabolic power paradigm ecologically valid within elite Gaelic football? Sport Sci. Health 2021. [CrossRef]

14. Ryan, M.; Malone, S.; Collins, K. Acceleration Profile of Elite Gaelic Football Match Play. J. Strength Cond. Res. 2018, 32, 812-820. [CrossRef]

15. Malone, S.; Hughes, B.; Roe, M.; Mangan, S.; Collins, K. Factors that Influence Session-Rating of Perceived Exertion in Elite Gaelic Football. J. Strength Cond. Res. 2020, 34, 1176-1183. [CrossRef]

16. Gallo, T.; Cormack, S.; Gabbett, T.; Williams, M.; Lorenzen, C. Characteristics impacting on session rating of perceived exertion training load in Australian footballers. J. Sports Sci. 2014, 33, 467-475. [CrossRef]

17. McGahan, J.; Burns, C.; Lacey, S.; Gabbett, T.; O’Neill, C. Relationship between load and readiness to train in a Gaelic football pre-competition training camp. Aust. J. Strength Cond. 2019, 27, 28-35.

18. Akubat, I.; Patel, E.; Barrett, S.; Abt, G. Methods of monitoring the training and match load and their relationship to changes in fitness in professional youth soccer players. J. Sports Sci. 2012, 30, 1473-1480. [CrossRef]

19. Banister, E.W. Modelling elite athlete performance. In Physiological Testing of Elite Athletes; Green, H.J., McDougall, J.D., Wagner, H.A., Eds.; Human Kinetics: Champaign, IL, USA, 1991; pp. 403-424.

20. Bompa, T.O.; Haff, G.G. Periodization: Theory and Methodology of Training, 5th ed.; Human Kinetics: Champaign, IL, USA, 2009.

21. Foster, C. Monitoring training in athletes with reference to overtraining syndrome. Med. Sci. Sports Exerc. 1998, 30, 1164-1168. [CrossRef]

22. Maddison, R.; Ni Mhurchu, C. Global positioning system: A new opportunity in physical activity measurement. Int. J. Behav. Nutr. Phys. Act. 2009, 6, 73. [CrossRef] [PubMed]

23. Hopkins, W.G. A spreadsheet for deriving a confidence interval, mechanistic inference, and clinical inference from a p-value. Sports Sci. 2007, 11, 16-20.

24. Rogalski, B.; Dawson, B.; Heasman, J.; Gabbett, T.J. Training and game loads and injury risk in elite Australian footballers. J. Sci. Med. Sport 2013, 16, 499-503. [CrossRef] [PubMed]

25. Reilly, T.; Collins, K. Science and the Gaelic sports: Gaelic football and hurling. Eur. J. Sport Sci. 2008, 8, 231-240. [CrossRef] 
26. Gabbett, T.J. The training-injury prevention paradox: Should athletes be training smarter and harder? Br. J. Sports Med. 2016, 50, 273-280. [CrossRef] [PubMed]

27. Gabbett, T.J. How Much? How Fast? How Soon? Three Simple Concepts for Progressing Training Loads to Minimize Injury Risk and Enhance Performance. J. Orthop. Sports Phys. Ther. 2020, 50, 570-573. [CrossRef]

28. Slattery, K.M.; Wallace, L.K.; Bentley, D.J.; Coutts, A.J. Effect of training load on simulated tram sport match performance. Appl. Physiol. Nutr. Metab. 2012, 37, 315-322. [CrossRef] [PubMed]

29. Malone, S.; Hughes, B.; Collins, K.; Akubat, I. Methods of Monitoring Training Load and Their Association With Changes Across Fitness Measures in Hurling Players. J. Strength Cond. Res. 2020, 34, 225-234. [CrossRef] 